\title{
Reflective Practice: Moving Intention into Action
}

\author{
Maxi Miciak and Michelle M. Lavoie \\ University of Alberta, Edmonton, Alberta, Canada
}

Gail V. Barrington

Barrington Research Group, Inc., Calgary, Alberta, Canada

\begin{abstract}
Reflection is a pillar of professional practice and can enable evaluators to expand their assumptions, change behaviour, and align practice with their values and beliefs. Reflective Practice is the first domain in the Canadian Evaluation Society's Competencies for Evaluation Practice, highlighting the importance of professional awareness and growth. However, the literature offers few tools to move reflective thought into action. The authors developed a personalized reflective approach through a mentoring relationship and the innovative use of a smartphone. Meaningful reflective practice can leverage personal experience, practical tools, and regular dialogue with a significant other to expand assumptions and change behaviour.
\end{abstract}

Keywords: evaluation, professional competency, reflection, reflective practice

Résumé : La réflexion est à la base même de la pratique professionnelle et peut permettre aux évaluateurs et aux évaluatrices de formuler de nouvelles hypothèses, de changer leur comportement et de faire correspondre leur pratique avec leurs valeurs et leurs convictions. La pratique réflexive est la première des compétences recherché par la Société canadienne dévaluation, ce qui montre bien l'importance de la conscience et de la croissance professionnelles. Cependant, il y a peu de documentation offrant des outils permettant de traduire les pensées réflexives en actions concrètes. Les auteures ont mis au point une approche réflexive personnalisée qui fait appel à une relation de mentorat et à une utilisation novatrice d'un téléphone intelligent. Une pratique réflexive judicieuse permet de tirer parti de l'expérience personnelle, d'outils pratiques et d'un dialogue continu avec une autre personne pour modifier des opinions préconçues et des comportements.

Mots clés : évaluation, compétences professionnelles, réflexion, pratique réflexive

Reflection is a pillar of professional practice and can enable evaluators to expand their assumptions, change their behaviour, and align their practice with their values and beliefs. It involves the conscious observation and critical assessment of one's attitudes, context, emotions, and thoughts in order to change behaviour and improve practice (Finlay, 2008; Knightbridge, 2019; Paterson \& Chapman, 2013).

Corresponding author: Maxi Miciak, University of Alberta, Faculty of Rehabilitation Medicine, 8205114 Street, 3-48 Corbett Hall, Edmonton, Alberta T6G 2G4, Canada; maxi@ ualberta.ca

(C) 2021 Canadian Journal of Program Evaluation / La Revue canadienne d'évaluation de programme 36.1 (Spring / Printemps), 95-105 doi: 10.3138/cjpe.69771 
Innovative and responsive professional practice relies upon practitioners taking responsibility for lifelong learning and, therefore, taking steps to develop a reflective practice that exposes taken-for-granted knowledge and actions (Finlay, 2008; Ganly, 2018). Although the importance of reflection is acknowledged in such fields as evaluation, health, and education (Canadian Evaluation Society, 2018; Kinsella, 2001; Knightbridge, 2019; Mann, Gordon, \& MacLeod, 2009; National Physiotherapy Advisory Group, 2017; Paterson \& Chapman, 2013; Patton, 2002), ways to develop reflective skills and enact meaningful reflection are few in number and tend to be vague and abstract (Knightbridge, 2019). Most practitioners would say they do reflect, but whether their internal processes result in meaningful and possibly transformative practice change is debatable.

Reflective Practice in Canada is highlighted as one of the five domains in the Canadian Evaluation Society (CES) Competencies for Evaluation Practice (CES, 2018, p. 5). The domains are as follows: (1) Reflective Practice, (2) Technical Practice, (3) Situational Practice, (4) Management Practice, and (5) Interpersonal Practice. To become a Credentialed Evaluator (CE), evaluators must prepare a portfolio that demonstrates their competence in each domain. Reflective Practice is described as follows:

competencies focus on the evaluator's knowledge of evaluation theory and practice; application of evaluation standards, guidelines, and ethics; and awareness of self, including reflection on the implications of one's practice and the need for continuous learning and professional growth. (CES, 2018, p. 6)

Further, sub-competency 1.7 states that the individual "[u]ses self-awareness and reflective thinking to continually improve practice” (CES, 2018, p. 6).

In this Practice Note, we illustrate how the first author (Maxi) advanced her evaluation practice by developing an individualized reflection approach within a mentoring relationship and adapting a strategy she had previously used in a different context. First, we provide some relevant theoretical perspectives to situate the authors' experiences developing and implementing a personalized reflective practice. Next, we describe the mentoring relationship that prompted the development of this approach. Then we describe the process itself and how it came to be. We reflect on the successes and challenges experienced and conclude with thoughts about the opportunities an individualized reflective process can offer.

\section{THEORIES AND MODELS OF REFLECTION AND REFLECTIVE PRACTICE}

\section{Theories of reflection and critical thought}

Deeper insights into the social processes that facilitate learning and growth can be elicited by situating lived experiences within a theoretical framework. Through their theoretical perspectives, John Dewey (education), Paulo Freire (education), 
and Donald Schön (professional practice) offer insight into the development, content, and implementation of Maxi's personalized reflective process.

Dewey, a key scholar of reflective and critical thought, provided the groundwork for many subsequent theories and models. He makes reflective, critical thought explicit through his five-step process (Dewey, 1933). According to Dewey, a reflective thinker becomes conscious of a problem, defines the scope of the problem, seeks potential solutions from past experience, plans a path forward, and tests for effective solutions. This process helps us respond in the present by drawing on past and present experience to direct future action. Further, Dewey (1938) argues that all experience is interactive (social), situational (contextual), and continuous (temporal), helping us recognize the unfolding, emergent quality of experience in which reflective practice takes place.

Drawing on Dewey's ideas of critical and reflective thought, Freire's theory expands into dialogue and critical consciousness. Freire's (2005) thoughts on dialogic learning stress reflective practice and the importance of learning in relation to another (e.g., a mentor) and learning in relation to personal experience (i.e., the thought-to-action-to-thought cycle). For Freire, learning is always social (Freire, 2005; Patton, 2017). Thoughts and actions are generated in relation to others-a dialogic process in which reflective thought and reflective action interact in a continuous loop over time. Thinking critically, one can assess whether thoughts and actions are relevant and beneficial.

Schön expands Dewey's ideas of reflective thought to characterize reflective practice for practitioners. His approach is operational, making implicit practice knowledge and action explicit and accessible to practitioners (Finlay, 2008; Schön, 1983). Specifically, he names reflection-in-practice, or conscious awareness in the midst of practice, and reflection-on-practice, or taking time to evaluate practice after the fact, as the cornerstones for leveraging the implicit professional artistry necessary for nimble and innovative problem solving (Finlay, 2008). These complementary processes illuminate problems, build competence, and advance practice.

\section{Reflective practice models in evaluation}

Dewey's writing on critical reflective thought and Schön's writing on critical reflective practice are the basis for various subsequent models. Despite the importance placed on reflective practice, ways to develop and enact reflective skills can be unclear due to the complexity of the process (Knightbridge, 2019). Cultivating self-awareness is meant to enable targeted actions in practice and promote lifelong learning (Finlay, 2008; Ganly, 2018). Two reflective practice models described in the evaluation literature include Kundin's (2010) conceptual framework on everyday decision-making and the DATA (Describe, Analyze, Theorize, and Act) model (Peters, 1991; Smith, Barlow, Peters, \& Skolits, 2015).

Kundin (2010) explores how evaluators make decisions about what approaches to take when assessing a particular evaluation situation. The three elements of this model are situational awareness and the context of the evaluation; practical 
reasoning, or the belief about what ought to be done; and reflection in action in everyday practice, making connections among knowledge, experiences, feelings, and their theories-in-use. As Schön (1983, p. 68) states, "When someone reflectsin-action, he becomes a researcher in the practice context. He is not dependent on the categories of established theory and technique, but constructs a new theory of the unique case."

Smith et al. (2015) see reflective practice as a tool for professional growth and learning. The DATA model (Peters, 1991) can be used to think through one's practice. Originally developed as a teaching tool for adult educators, it has been used by practitioners to enhance individual and collaborative reflective practice because of its action focus. Its value lies in its interactive nature, allowing one to describe what exists, analyze the situation, theorize about what action to take, and then act based on this reasoned judgment-in any sequence and with any number of iterations. The goal is to construct a plausible explanation for the practice problem, which then informs a practical solution (Smith et al., 2015).

\section{THE MENTORSHIP PARTICIPANTS AND PROCESS}

The first and second authors (Maxi and Gail) began their mentoring relationship in 2015, at the request of Maxi's employer, as part of Maxi's postdoctoral fellowship. They came from very different backgrounds. Maxi, a physiotherapist with 15 years of clinical experience, completed a doctorate in Rehabilitation Science at the University of Alberta in 2015. She then began a postdoctoral fellowship studying research impact assessment at Alberta Innovates. The fellowship involved learning about evaluation theory and practice. Gail started her consulting firm, Barrington Research Group, Inc., in 1985. Since then she has conducted over one hundred program evaluation studies, mainly in education, health, and research. She teaches qualitative research, mixed methods, and program evaluation. She has served on the CES Credentialing Board for many years, and this experience provided the impetus for their mentoring relationship.

Gail agreed to assist Maxi in preparing for the CE designation, making it clear that she would absent herself from any aspect of the review process of Maxi's credential application.

The two met once a month by teleconference between September 2015 and August 2018. The CE Competencies offered a framework for their discussion, allowing Maxi to examine her challenges and successes as she experienced evaluation in the field while providing a structure to guide learning and application of the required competencies. Over time, much of their discussion came to focus on reflective practice.

\section{DEVELOPING A PERSONAL REFLECTIVE PRACTICE}

Gail believes that evaluators can apply their skills of observation and analysis to themselves, using critical incidents and past mistakes as catalysts for positive 
practice change. Her own method of reflection is written journaling, using the "Morning Pages" technique (Cameron, 1992). This involves producing three pages of longhand, stream-of-consciousness writing immediately upon waking. She has used this method for many years and believes it has fostered her creativity, provided insight, and enhanced her evaluation practice. It was not surprising, then, that she encouraged Maxi to use a similar process.

Maxi was familiar with reflection because a "reflective approach to practice" is a key physiotherapy competency (National Physiotherapy Advisory Group, 2017). She had also used written journaling as a reflexivity strategy in her qualitative doctoral research (Finlay, 2003; Mayan, 2009). Reflexivity is "the process of being highly attentive to how and why you make decisions and interpretations along the research way" (Mayan, 2009, p. 137) and implicitly involves a reflective process. Given Maxi's success with written journaling, both she and Gail thought it would be easy to apply in her evaluation practice. Surprisingly, this was not the case.

During their monthly conversations, Gail would ask, "So how's the journaling going, Maxi?" Maxi's responses highlighted the difficulties she encountered over a period of several months, as these comments from Gail's meeting notes reveal:

December 6, 2016

Struggling. Still inconsistent. I need a different structure ... an entry point.

January 17, 2017

Sometimes very vanilla. It helps when we articulate. I made a few notes as we talked.

February 21, 2017

It sucks. I'm not disciplined. (Barrington, 2018)

Maxi and Gail "reflected on reflecting" through dialogue, taking time to analyze barriers to adopting writing as a reflection tool. They noted that even though Maxi had previously used and valued writing, this situation was different. Their conversation revealed that Maxi was challenged to use writing as a reflective method, constrained by time and focus within a busy work context. They also discovered that Maxi found writing to be cognitive and analytical, whereas, as she reflected, "when I am moving I start to talk to myself and things come out. That's where the better ideas come from" (Barrington, 2018). She recalled that during her doctoral research she had recorded her thoughts as voice memos on her smartphone. As she explained,

If I am talking to myself, I can turn my phone on anywhere. I can do a brain dump and say, "OK, what did I just talk about? What action needs to come from that? What do I need to do with it?" I could reflect on what I just recorded and make meaning out of it, sum it up, ask, "So now what?" (Barrington, 2018)

Maxi began recording voice memos about her evaluation experiences on her smartphone. Gail supported her experimentation with this approach, and a new 
Table 1. A description of Maxi's personal six-step reflective process using voice memoing on a smartphone

\begin{tabular}{lll}
\hline Step & Description \\
\hline 1 & Verbalize & $\begin{array}{r}\text { Articulate a "brain dump" or free flow of thoughts and feelings } \\
\text { about a current situation (e.g., a challenge in a project) while } \\
\text { recording on the smartphone. This is unfiltered verbalization. } \\
\text { No critical analysis is needed. }\end{array}$ \\
2 & Interpret & $\begin{array}{l}\text { Interpret the organic descriptions in Step } 1 \text { by intentionally } \\
\text { summarizing them. }\end{array}$ \\
3 & Synthesize & $\begin{array}{l}\text { Combine summaries into a theme, assigning a title for the audio file } \\
\text { Determine an action that can be taken into practice as soon as } \\
\text { possible. }\end{array}$ \\
5 & Plan & $\begin{array}{l}\text { Act } \\
\text { Implement the action identified in Step 4, taking it into practice. }\end{array}$ \\
\hline
\end{tabular}

type of reflective practice began to take shape. Maxi found that her mind was sharp in the morning while walking to the train. She could more deeply access information when simultaneously thinking, speaking, and walking. The process was efficient, versatile, and comfortable, and it aligned with her current needs.

The two analyzed Maxi's voice-memoing process in their monthly discussions. They noticed a pattern in the memos-the intentionality of the "thinking" and "doing" aspects of reflection. They also talked about reflective practice from a theoretical perspective; in particular, they discussed Schön's (1983) ideas about reflection-in-practice and reflection-on-practice. From there, a personal six-step reflective process crystallized. Table 1 outlines the six reflection concepts experienced by Maxi: verbalize, interpret, synthesize, plan, act, and reflect.

\section{REFLECTING ON PRACTICE IN ACTION}

Maxi focused her reflections on developing her leadership skills. Increasingly, she was being placed in leadership roles, such as leading projects and chairing meetings. She began observing leaders in action to develop her own leadership skills. She said, "I don't want to be a leader by default, but by intent. I am looking at leaders, seeing how they maneuver in different situations" (Barrington, 2018). She also began observing herself in action. For example, she recalled chairing a meeting where she "sensed someone was uncomfortable with the timeline and mentioned it, opening a conversation to get clarity. I am building my negotiating and consensus building skills" (Barrington, 2018). Maxi also found herself being more transparent and direct when leading projects. Gail asked her, "Could you have done this a year ago?" She answered, "No, I would not have felt confident enough" (Barrington, 2018).

Between October 24 and November 21, 2017, Maxi began to record voice memos on leadership. Examples of file names during this period included "Attitude 
of a leader," "Engaging and empowering a team," and "Negotiating, building consensus and authentic asking." During that short period, Maxi sensed significant growth. She and Gail began to reflect on her reflections in dialogue. They realized that setting an intention was essential for Maxi's ability to shift her practice, as she conveyed:

even the intent, summarizing and pulling it together, even if you don't follow through on the exact action, it moves you forward to do something. There is all this thinking and processing that creates the momentum to move it forward. The intent is not a "To Do" list-being intentional with thoughts, feelings, and what you sense, and putting out what you want to put out-the idea that what you put out comes back to you and you recognize it. (Barrington, 2018)

As the months passed, Maxi and Gail continued to debrief monthly about Maxi's application of her six-step process. By May 2018, she was reflecting on her leadership skills in a grant application process, as this excerpt from Gail's meeting notes describes:

I did a walk and talk voice memo reflecting on leadership and cultivating my leadership skills and the qualities needed to lead a team writing a grant. It was a unique call and we had a very short turn around as well as some other bureaucratic obstacles to overcome. As I was brain-dumping all of these challenges, I recognized that my tendency is to have a defeatist attitude when faced with what I perceive as an insurmountable challenge. I said to myself, "Leaders don't have defeatist attitudes, they embrace challenges." As I thought about that, I became aware this was not feeling very great... I talked it out and ... it allowed a moment for an idea to come forth. The idea was that I could be aware of my states and attitudes, and I needed to shift my attitude to "Leaders welcome challenges and meet them head on." I took this attitude straight into work and noticed how it changed my approach from passive to assertive, a "get it done" sensibility. I was then more aware when I started to shift back into a passive demeanor and tried to re-assert myself. We got our proposal done and submitted before the deadline. It was a very cogent, clear proposal. When we clicked the send button, [I thought,] "Wow, it was possible because we did it!" I am so proud. I was leading it, it was going to be a challenge, and we got it done. (Barrington, 2018)

In addition to the reflective process having a positive influence on Maxi's leadership attitudes and behaviours, another clear impact emerged. Maxi believed that Steps 1-4 enabled her to understand her leadership patterns. Reviewing the titles of the voice-memo files saved on the smartphone (Step 3), she learned that her leadership style was relational. Some of her leadership behaviours also changed or were reinforced in Step 5. For example, one reflection explored what it meant for leaders to be genuine in their interactions. As a result, Maxi determined that she would express more of her personality instead of acting the way she thought she should act as a leader. She began to be herself and to explore what exactly being herself meant in the context of her leadership. Step 6 provided space to acknowledge that being herself had generally resulted in feeling more comfortable 
in leadership situations. She no longer felt the need to impress or have the answer, which allowed her to facilitate engagement and express herself clearly.

Some aspects of the six-step process proved challenging to implement. While Maxi found Steps 1-4 easy to enact and monitor, she was less clear about Steps 5-6, or Schön's (1983) reflecting-in-practice. Did she consciously reflect-in-practice and adapt based on these reflections? Schön (1983) claims that practitioners implicitly reflect and adapt during practice to solve problems. She thinks it is likely that she did because she primed herself by determining and carrying out an action in a real-world situation. A next step for developing Maxi's reflective practice could be to become more aware of how she reflects and adjusts during practice.

The mentoring dialogue between Maxi and Gail helped to clarify and integrate the former's reflective practice. Over their three-year relationship, the authors developed a systematic and personally meaningful reflective process that Maxi applied consistently and with increased ease. She was able to refine and apply the ideas they generated by critically reflecting on her practice, judging, synthesizing, and then acting on her critical thought. She could also assess her skill development by noting the progress in her thought patterns and emotional responses as illustrated by the voice memo file names.

\section{OPPORTUNITIES FOR EVALUATION PRACTICE}

While developing Maxi's reflective process, she and Gail made important realizations that have implications for evaluation practice. First, the importance of reflective practice as an evaluator competency has been reinforced and the value of having a personal reflective practice confirmed. Second, the use of a framework or model adds structure, deepens learning, and facilitates behaviour change. In addition, developing an innovative reflective practice that matches personal values, resources, and circumstances can enhance one's commitment to the process. Finally, reflecting in relationship, such as with a mentor, can result in significant learning, which can then be transformed into meaningful action. This organic, inductive, and iterative dialogue generated a reflective practice that resulted in transformative change.

While preparing this article, the authors further conceptualized the whole experience of advancing Maxi's reflective competency (see Figure 1). Figure 1 provides a summary of the key aspects of the authors' journey. Others who wish to advance their reflective practice may find these factors useful as they can apply or modify them to their own context.

\section{CONCLUSION}

Reflection is a key competency for advancing evaluation practice because it helps us improve our responses to situations and contexts, both in the moment and afterwards. Models and frameworks can provide the structure necessary to move thoughts into action. A personal reflective practice may need to take various 


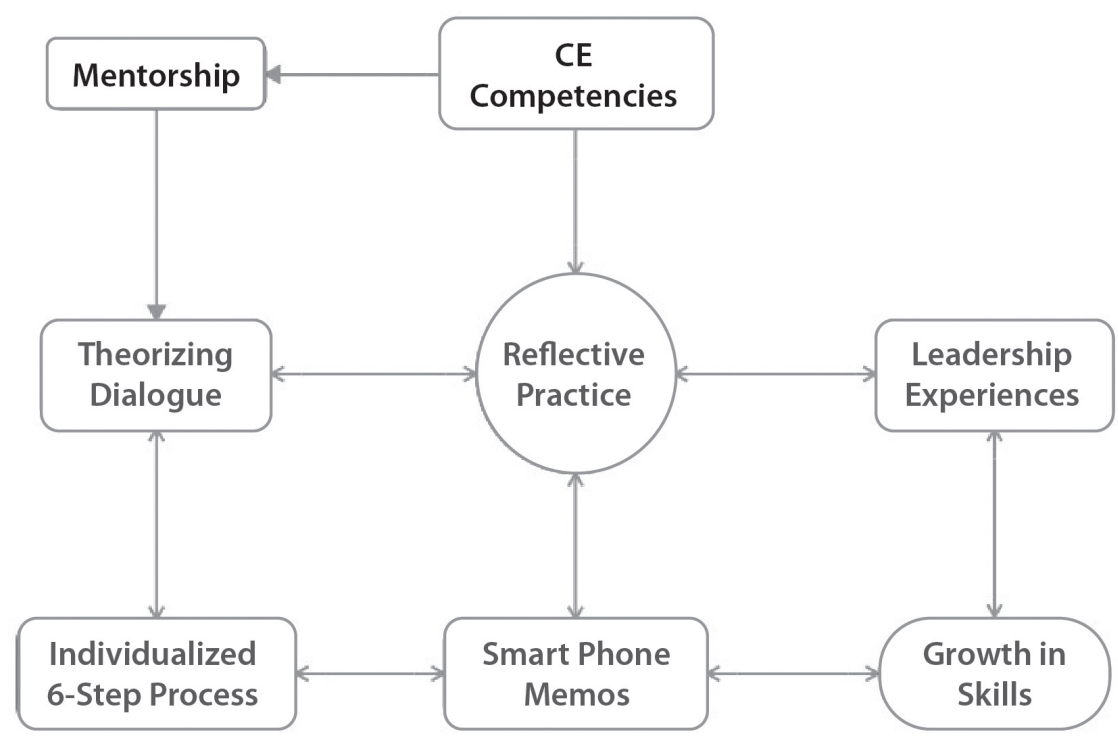

Figure 1. Factors for enhancing reflective practice

shapes and integrate different tools depending on the context, needs, values, and experiences of the evaluator. In their mentoring relationship, Maxi and Gail were able to theorize about Maxi's unique experience. This enabled her to respond to a growing interpretation of her leadership skills in the moment and afterwards (Schön, 1983) using a dialogic process (Freire, 2005) to help frame her future action (Dewey, 1933). The result was a personally appropriate six-step reflection process using her smartphone. While established frameworks may resonate with evaluators, they should also be open to adapting them based on their circumstances. Our experience showed us that meaningful reflective practice can leverage innovative tools (e.g., a smartphone) and regular dialogue with a significant other (e.g., a mentor) to expand an evaluator's assumptions and change their behaviour while professional knowledge and skills grow.

\section{REFERENCES}

Barrington, G. V. (2018). Notes taken during mentorship meetings between Maxi and Gail. Calgary, AB: Barrington Research Group, Inc.

Cameron, J. (1992). The artist's way: A spiritual path to higher creativity. New York, NY: Tarcher/Penguin.

Canadian Evaluation Society (CES). (2018). Competencies for Canadian evaluation practice. Retrieved from https://evaluationcanada.ca/txt/2_competencies_cdn_evaluation_ practice_2018.pdf

Dewey, J. (1933). How we think: A restatement of the relation of reflective thinking to the educative process (2nd ed.). Boston, MA: D. C. Heath. 
Dewey, J. (1938). Experience and education. New York, NY: Collier Books.

Finlay, L. (2003). The reflexivity journey: Mapping multiple routes. In L. Finlay \& B. Gough (Eds.), Reflexivity: A practical guide for researchers in health and social sciences (pp. 3-20). Oxford, England: Blackwell Science.

Finlay, L. (2008). Reflecting on "reflective practice." Practice-based professional learning center paper 52. The Open University. Retrieved from http://ncsce.net/wp-content/ uploads/2016/10/Finlay-2008-Reflecting-on-reflective-practice-PBPL-paper-52.pdf

Freire, P. (2005). Pedagogy of the oppressed: 30th anniversary edition (M. B. Ramos Trans.). New York, NY: Continuum (Original work published 1970).

Ganly, T. (2018). Taking time to pause: Engaging with a gift of reflective practice. Innovations in Education and Teaching International, 55(6), 713-723. https://doi.org/10.108 0/14703297.2017.1294492

Kinsella, E. A. (2001). Reflections on reflective practice. Canadian Journal of Occupational Therapy, 68(3), 195-198. https://doi.org/10.1177/000841740106800308. Medline: 11433918

Knightbridge, L. (2019). Reflection-in-practice: A survey of Australian occupational therapists. Australian Occupational Therapy Journal, 66(3), 337-346. https://doi. org/10.1111/1440-1630.12559. Medline:30680734

Kundin, D. M. (2010). A conceptual framework for how evaluators make everyday practice decisions. American Journal of Evaluation, 31(3), 347-362. https://doi. org/10.1177/1098214010366048

Mann, K., Gordon, J., \& MacLeod, A. (2009). Reflection and reflective practice in health professions education: A systematic review. Advances in Health Sciences Education, 14(4), 595-621. https://doi.org/10.1007/s10459-007-9090-2. Medline:18034364

Mayan, M. (2009). Essentials of qualitative inquiry. Walnut Creek, CA: Left Coast Press.

National Physiotherapy Advisory Group. (2017). Competency profile for physiotherapists in Canada. Retrieved from https://peac-aepc.ca/pdfs/Resources/Competency\%20 Profiles/Competency\%20Profile\%20for\%20PTs\%202017\%20EN.pdf

Paterson, C., \& Chapman, J. (2013). Enhancing skills of critical reflection to evidence learning in professional practice. Physical Therapy in Sport, 14(3), 133-138. https:// doi.org/10.1016/j.ptsp.2013.03.004. Medline:23643448

Patton, M. Q. (2002). Qualitative research \& evaluation methods (3rd ed.). Thousand Oaks, CA: Sage Publications.

Patton, M. Q. (2017). Pedagogical principles of evaluation: Interpreting Freire. New Directions for Evaluation, 155, 49-77.https://doi.org/10.1002/ev.20260

Peters, J. M. (1991). Strategies for reflective practice. New Directions for Adult \& Continuing Education, 51, 89-96. https://doi.org/10.1002/ace.36719915111

Schön, D. A. (1983). The reflective practitioner. New York, NY: Basic Books.

Smith, T. L., Barlow, P. B., Peters, J. M., \& Skolits, G. J. (2015). Demystifying reflective practice: Using the DATA model to enhance evaluators' professional activities. Evaluation and Program Planning, 52, 142-147. https://doi.org/10.1016/j.evalprogplan.2015.04.004. Medline:26051793 


\section{AUTHOR INFORMATION}

Maxi Miciak strives to positively influence patient care and the use of research evidence in health system decision making. Drawing upon her experiences as a physical therapist, Maxi's research interests probe the factors that influence provision of care from social and systems perspectives. Her conceptual framework of the therapeutic relationship in physical therapy is being used in research with uptake in entry-to-practice and postgraduate education and clinical practice. Her expertise has resulted in numerous invitations to speak at local, national, and international webinars, events, and conferences in physical therapy and inter-professionally. Maxi is also advancing the nascent area of research impact assessment. She has collaborated with local, national, and international health-system stakeholders and is currently working with organizations to develop and implement research impact frameworks. Maxi is Principal of Maxi Miciak Consulting and an adjunct associate professor in the Faculty of Rehabilitation Medicine, University of Alberta.

Gail Vallance Barrington teaches program evaluation and research methods to Master's students at the University of Alberta and Michigan State University. From 1985 to 2018 she managed Barrington Research Group, Inc., and conducted over 130 program evaluation studies, mainly in education, health, and research. Based on her consulting experience, she wrote her popular book, Consulting Start-up and Management: A Guide for Evaluators and Applied Researchers (SAGE, 2012). She is a Credentialed Evaluator and has served on the Canadian Evaluation Society's Credentialing Board since its inception in 2010. She is currently co-authoring an introductory text on program evaluation.

Michelle M. Lavoie is a doctoral candidate in the Department of Educational Policy Studies, Faculty of Education, University of Alberta, Edmonton. Her research focuses on understanding arts-based mentorship as a collaborative teaching and learning experience to support vulnerable populations; co-creating relational assets for adult learners; highlighting practical applications of adult learning theories; and developing visual narrative inquiry methodology. Michelle is supported in part by funding from the Social Sciences and Humanities Research Council (SSHRC). 